\title{
Obstructive and Central Sleep Apnea in First Ever Ischemic Stroke are Associated with Different Time Course and Autonomic Activation
}

\author{
Alessia Riglietti, ',* \\ Francesco Fanfulla, $\mathbb{D}^{2, *}$ \\ Massimo Pagani, ${ }^{3}$ \\ Daniela Lucini, $\mathbb{1}^{3,4}$ \\ Mara Malacarne, (iD) 3,4 \\ Mauro Manconi, (iD ${ }^{5-7}$ \\ Guido Ferretti, ${ }^{8,9}$ \\ Fabio Esposito, (1D ${ }^{10,11}$ \\ Carlo W Cereda, ${ }^{12}$ \\ Marco Pons' \\ 'Department of Pulmonology, Regional \\ Hospital of Lugano (EOC), Lugano, 6900, \\ Switzerland; ${ }^{2}$ Respiratory Function and \\ Sleep Unit - Istituti Clinici Scientifici Maugeri \\ IRCCS, Pavia, Italy; ${ }^{3}$ Exercise Medicine Unit, \\ Istituto Auxologico Italiano, Mllan, 20I33, \\ Italy; ${ }^{4}$ University of Milan, BIOMETRA \\ Department, Milan, Italy; ${ }^{5}$ Sleep and Epilepsy \\ Center, Neurocenter of the Southern \\ Switzerland, Regional Hospital (EOC) of \\ Lugano, Lugano, Switzerland; ${ }^{6}$ Faculty of \\ Biomedical Sciences, Università della \\ Svizzera Italiana, Lugano, Switzerland; \\ ${ }^{7}$ Department of Neurology, University \\ Hospital, Inselspital, Bern, Switzerland; \\ ${ }^{8}$ Department APSI, University of Geneva, \\ Geneva, Switzerland; ${ }^{9}$ Department of \\ Molecular and Translational Medicine, \\ University of Brescia, Brescia, Italy; \\ ${ }^{10}$ Department of Biomedical Sciences for \\ Health, Università degli Studi di Milano, \\ Milan, Italy; "IRCCS Istituto Ortopedico \\ Galeazzi, Milan, Italy; '2Stroke Center EOC, \\ Department of Neurology, Neurocenter of \\ Southern Switzerland Regional Hospital \\ (EOC) of Lugano, Lugano, Switzerland \\ *These authors contributed equally to this \\ work
}

Correspondence: Mauro Manconi Regional Hospital of Lugano, Via

Tesserete, 46, Lugano, 6903, Switzerland

Tel +4I-9I-8II6825

Email mauro.manconi@eoc.ch
Introduction: Sleep-related breathing disorders are highly prevalent in patients with ischemic stroke. Among sleep-disordered breathing disorders, obstructive sleep apnea is the most represented one, but central sleep apnea, isolated or in the context of a periodic breathing/Cheyne-Stokes respiration, is frequently reported in these patients. Altered baroreflex responses have been reported in the acute phases of a cerebral event.

Methods: We conducted, in a group of patients with ischemic stroke $(n=60)$, a prospective 3-month follow-up physiological study to describe the breathing pattern during sleep and baroreflex sensitivity in the acute phase and in the recovery phase.

Results: In the acute phase, within 10 days from the onset of symptoms, $22.4 \%$ of patients had a normal breathing pattern, 40.3\% had an obstructive pattern, $16.4 \%$ had a central pattern, and $29.9 \%$ showed a mixed pattern. Smaller variations in the Apnea-Hypopnea Index were found in normal breathing and obstructive groups $(\triangle \mathrm{AHI} 2.1 \pm 4.1$ and $-2.8 \pm 11.6$, respectively) in comparison with central and mixed patterns $(\triangle \mathrm{AHI}-6.9 \pm 15.1$ and -12.5 \pm 13.1 , respectively; ANOVA $p=0.01$ ). The obstructive pattern became the most frequent pattern, in $38.3 \%$ of patients at baseline and $61.7 \%$ of patients at follow-up. Modification of baroreflex sensitivity over time was influenced by the site of the lesion and by the sleep disorder pattern in the acute phase (MANOVA $p=0.005$ ).

Conclusion: We suggest that a down-regulation of autonomic activity, possibly related to reduced vagal modulation, may help the recovery after stroke, or a transitory disconnection from the cortical node that participates in the regulation of sympathetic outflow.

Keywords: sleep-disordered breathing, baroreflex, chemoreflex, brain lesion

\section{Introduction}

Sleep-disordered breathing (SDB) and stroke are bidirectionally linked, as obstructive sleep apnea (OSA) is a recognized risk factor for stroke, and, on the other hand, stroke may trigger a new or worsen a pre-existing SDB disorder. Around 50\% of patients with stroke suffer from SDB in their acute post-ischemic course. Obstructive sleep apnea (OSA) is certainly the most frequently occurring SDB disorder. ${ }^{1-5}$ Nevertheless, a clear central breathing component, consisting of a series of central sleep hypopnea/apneas (CSAs), or clustered in periodic breathing/Cheyne-Stokes respiration, is present in $40 \%$ of the patients, either alone or mixed with an obstructive component. ${ }^{6}$ Most of the available literature about the pathophysiological mechanism behind sleep-related central breathing disorders comes from studies on patients with heart failure. A few studies have investigated the putative causal relationship between stroke and CSA. ${ }^{3,6,7}$ However, the 
results are still controversial and debated, in particular concerning the size and location of the brain damage that is more prone to cause CSA. Two prospective studies showed that SDB with a central pattern tends to improve spontaneously during the first few months after stroke, suggesting that the acute phase of the cerebrovascular event plays a key role in triggering CSA. ${ }^{7,8}$ Why and how stroke may induce or worsen a pre-existing central SDB are still unknown. In particular, the roles of baroreflexes and chemoreflexes in the control of breathing during stroke need to be elucidated.

In healthy humans, arterial baroreflex stimulation induced by an increase in arterial blood pressure increases parasympathetic vagal activity and inhibits sympathetic activity. Consequently, the heart rate is reduced, heart contractility is depressed, and total peripheral resistances and venous return fall. ${ }^{9}$

This regulatory mechanism seems to work also in the acute stage of ischemic cerebral events. ${ }^{9-12}$ The rationale behind the present study is that in patients with first ever ischemic stroke, the presence of central and/or obstructive sleep-related respiratory events is sustained by two different patterns of autonomic activity. In particular, we postulated the existence of a sustained activation of the sympathetic nervous system in acute stroke, enough to dampen the baroreflex response.

From a clinical viewpoint, CSA in the acute phase of stroke may be the result of an attenuated baroreflex activity, repressed during an emergency. On the other hand, CSA may represent an independent risk factor for ischemic events or a negative factor for stroke outcome. In this context, a baroreflex dysfunction would represent a negative prognostic factor in numerous clinical conditions such as myocardial infarction, heart failure, and stroke. ${ }^{13,14}$ Sykora et al considered the study of baroreflex in stroke a major challenge in neurophysiology, with a potentially crucial role in new therapeutic strategies. ${ }^{15,16}$

\section{Aims and Hypothesis}

The aims of the present prospective study were:

1. to assess sleep-related respiratory patterns in the acute and chronic phases of ischemic stroke

2. to test the baroreflex sensitivity in acute stroke

3. to verify whether a particular baroreflex response, assessed by the second aim, was related to a specific sleep breathing pattern and to a specific stroke location.

\section{Materials and Methods}

An extensive description of the methods is provided in the online supplementary file.

\section{Subjects}

From November 2012 to October 2015, 70 patients with a diagnosis of ischemic stroke were screened according to the following inclusion criteria: age range 18-75 years, ischemic stroke, and hospitalization in a stroke unit within 48 hours from the onset of neurological symptoms. The clinical diagnosis of stroke was established by a neurologist and confirmed by a brain MRI scan in all patients, and the severity was assessed by means of the National Institutes of Health Stroke Scale (NIHSS) and modified Rankin Scale. Patients with pulmonary or cardiocirculatory unstable clinical conditions, patients already on noninvasive mechanical ventilation in the 3 months preceding the stroke, and those with an impaired state of consciousness were excluded.

\section{Sleep Studies}

Daytime sleepiness was analyzed by the Epworth Sleepiness Scale (ESS). ${ }^{17}$ Nocturnal cardiorespiratory monitoring was performed using the ResMed nocturnal polygraphic device Nox T3 (Iceland) within 10 days from stroke onset (median time $3.4 \pm 1.4$ days), repeated after 3 months, and manually scored according to criteria defined by the American Society of Sleep Medicine. ${ }^{18,19}$

In the presence of an Apnea-Hypopnea Index (AHI) $\geq 5$, a patient was classified as follows:

1. dominant central sleep apnea (d-CSA) if $\geq 70 \%$ of the events were scored as central and the central AHI (AHIc) was $\geq 5$

2. dominant obstructive sleep apnea (d-OSA) if $\geq 70 \%$ of the events were obstructive in nature and the obstructive AHI (AHIo) was $\geq 5$

3. mixed respiratory pattern (MP) if less than $70 \%$ of the events could be scored as obstructive or central, and the global AHI was $\geq 5$.

Patients without respiratory pattern alterations $(\mathrm{AHI}<5)$ were classified as having no sleep-disordered breathing (No-SDB). 


\section{Pulmonary Function Tests and Autonomic Assessment}

At the time of enrollment, all patients underwent a complete lung function test. ${ }^{20}$ In the acute phase and at the end of follow-up, we obtained an indirect assessment of autonomic regulation of the sinus atrial node.

Cardiac autonomic performance was gauged from baroreflex gain using both, the time domain baroreflex sensitivity (BRS) and the frequency domain index alpha, and heart rate variability. The latter was also assessed by a unitary integrated Autonomic Nervous System Index (ANSI). Individual data points were quantified against a large benchmark population, with values ranging from 0 to 100 (higher values indicating better performance). ${ }^{21,22}$

\section{Statistical Analysis}

Data are presented as mean \pm standard deviation. ANOVA was performed to assess differences between the four different patterns of SDB and post-hoc analysis was performed to compare differences between groups. The $\chi^{2}$ test was used to compare the distribution of categorized variables. Pearson's linear correlation analysis was performed to assess which variables were correlated with sleep respiratory parameters.

The paired $t$-test was performed to establish changes between baseline and follow-up for all the indices considered. The analysis of variance for repeated measures (MANOVA) was applied to compare changes in AHI or autonomic indices between acute and chronic phase in the four groups of patients according to SDB pattern in the acute phase or site of lesion. Tukey's honest statistical difference test for unequal sample sizes (Spjotvoll \& Stoline test) and the Scheffé test were used to compare differences between groups and within groups, respectively.

\section{Results}

\section{Clinical Features}

Three out of the 70 screened patients were excluded for technical reasons and seven did not undergo the 3-month follow-up (Figure 1). The characteristics of the remaining 60 patients are reported in Tables 1 and 2 .

Forty-nine patients (73\%) presented arterial hypertension, whether already treated when hospitalized or newly diagnosed; 52 patients (78\%) presented hyperlipidemia, known or newly diagnosed, and 14 patients (21\%) had diabetes mellitus. Chronic obstructive pulmonary disease (COPD) was present in 13 patients (19\%) (11 stage GOLD I-II, 2 stage GOLD III-IV).

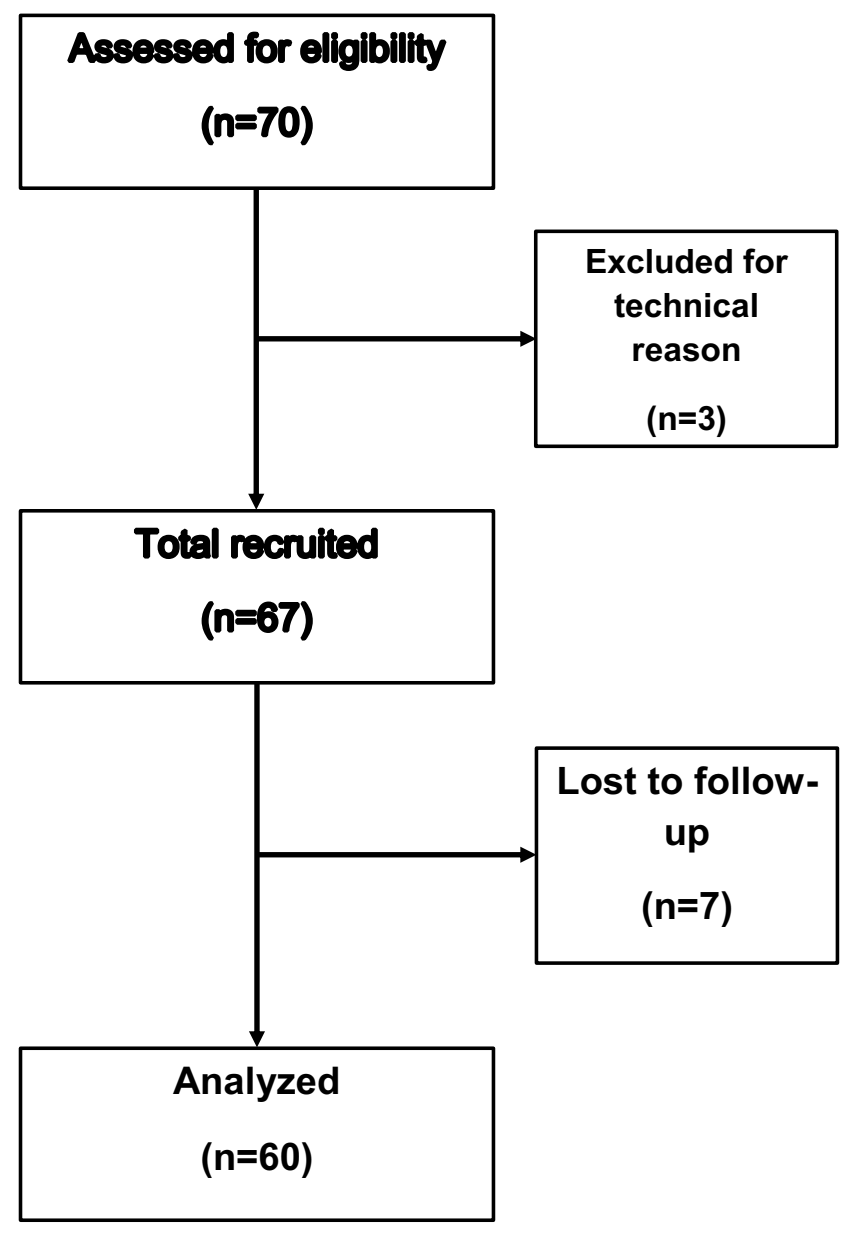

Figure I Flow diagram of the study.

Six patients presented paroxysmal atrial fibrillation during monitoring in the stroke unit but not during ECG recording for baroreflex analysis. One patient had cardiac failure (mean ejection fraction 60\%). Forty-eight patients had a supratentorial lesion at MRI, 15 had an infratentorial lesion, and four had supratentorial and infratentorial lesions.

\section{Acute Phase Clinical and Sleep Data}

Fifteen patients (22.4\%) had No-SDB, 27 (40.3\%) had a d-OSA pattern, 11 (16.4\%) had a d-CSA pattern, and 14 (20.9\%) showed a mixed pattern (MP). Overall, an AHI >10 was found in 48 patients $(71.6 \%)$ and an $\mathrm{AHI}>30$ was found in 15 patients $(22.4 \%)$. Cheyne-Stokes respiration $(>10 \%$ of total time) was found in $28.3 \%$ of patients at baseline: in $12 \%$ of patients with a predominant OSA, in $60 \%$ of patients with predominant CSA, and in $61.5 \%$ of patients with a mixed pattern $\left(\chi^{2}<0.001\right)$.

Tables 1 and 2 report the clinical and sleep data according to SDB pattern. No significant differences between 
Table I Demographic and Clinical Data

\begin{tabular}{|c|c|c|c|c|c|c|}
\hline & No-SDB $(n=15)$ & d-OSA $(n=27)$ & d-CSA $(n=I I)$ & $M P(n=14)$ & Total $(n=67)$ & $p$ \\
\hline Age (years) & $58.1 \pm 8.3$ & $62.2 \pm 9.9$ & $61.8 \pm 7.7$ & $60.2 \pm 11.8$ & $60.8 \pm 9.6$ & n.s. \\
\hline BMI $\left(\mathrm{kg} / \mathrm{m}^{2}\right)$ & $23.8 \pm 3.4$ & $28.1 \pm 4.3$ & $27 \pm 3.1$ & $27.6 \pm 4.5$ & $26.8 \pm 4.2$ & 0.01 \\
\hline NIHSS & $0.93 \pm 1.2$ & $1.1 \pm 2$ & $1.5 \pm 2.2$ & $1.3 \pm 1.6$ & $1.2 \pm 1.8$ & n.s. \\
\hline $\mathrm{EF}(\%)$ & $58.7 \pm 7.2$ & $60.2 \pm 3.7$ & $58.2 \pm 6.8$ & $60.7 \pm 5.3$ & $59.6 \pm 5.5$ & n.s. \\
\hline FVC (\%) & $104.3 \pm 18$ & $95.9 \pm 20$ & $103.4 \pm 15.1$ & $101.5 \pm 21.9$ & $100.1 \pm 19.3$ & n.s. \\
\hline $\mathrm{FEV}_{\mathrm{I}}(\%)$ & $96 \pm 19$ & $91 \pm 20.7$ & $100.9 \pm 14.5$ & $98.9 \pm 20.2$ & $95.4 \pm 19.7$ & n.s. \\
\hline $\mathrm{FEV}_{\mathrm{I}} / \mathrm{FVC}$ & $74.4 \pm 8.1$ & $76.3 \pm 8.6$ & $77.3 \pm 7.7$ & $78 \pm 6.9$ & $76.4 \pm 7.9$ & n.s. \\
\hline ESS & $7.4 \pm 4.7$ & $10 \pm 6.3$ & $6.7 \pm 3.5$ & $9.1 \pm 6.7$ & $8.7 \pm 5.7$ & n.s. \\
\hline Hypertension (\%) & 73.3 & 74.1 & 81.8 & 64.3 & 73.1 & n.s. \\
\hline Diabetes (\%) & 13.3 & 25.9 & 18.2 & 21.4 & 20.9 & n.s. \\
\hline
\end{tabular}

Note: Data are presented as mean \pm SD unless otherwise indicated.

Abbreviations: BMI, body mass index; NIHSS, NIH Stroke Scale; EF, ejection fraction; FVC, forced vital capacity; FEV Sleepiness Score; No-SDB, no sleep-disordered breathing; d-OSA, dominant obstructive sleep apnea pattern; d-CSA, dominant central sleep apnea pattern; MP, mixed pattern.

Table 2 Respiratory Polygraphic Indices

\begin{tabular}{|c|c|c|c|c|c|c|}
\hline & No-SDB $(n=15)$ & d-OSA $(n=27)$ & d-CSA $(n=I I)$ & $M P(n=14)$ & Total $(n=67)$ & $p$ \\
\hline $\mathrm{AHI}$ & $5.2 \pm 2$ & $22.6 \pm 14.7$ & $31.9 \pm 15.7$ & $27.9 \pm 16.9$ & $21.4 \pm 16.3$ & $<0.0001$ \\
\hline Supine AHI & $9.1 \pm 4.6$ & $35.1 \pm 18.3$ & $43.2 \pm 19.3$ & $43.9 \pm 22.6$ & $32.7 \pm 21.7$ & $<0.0001$ \\
\hline AHlo & $2.7 \pm 1.4$ & $20.6 \pm 15.1$ & $4.9 \pm 3.9$ & $14.3 \pm 9.9$ & $12.8 \pm 13$ & $<0.0001$ \\
\hline AHIc & $2.3 \pm 2$ & $2.4 \pm 2.9$ & $27.5 \pm 15.1$ & $13.4 \pm 8.3$ & $8.7 \pm 11.6$ & $<0.0001$ \\
\hline MCA s & $15 \pm 3.9$ & $14.6 \pm 2.2$ & $17.4 \pm 2.7$ & $16.1 \pm 2.4$ & $15.5 \pm 2.8$ & n.s. \\
\hline MOA s & $10 \pm 8.2$ & $19.3 \pm 4.6$ & $16.7 \pm 3.4$ & $15.9 \pm 3.1$ & $16 \pm 6.3$ & $<0.001$ \\
\hline Mean $\mathrm{SpO}_{2} \%$ & $93.1 \pm 1.7$ & $91.9 \pm 1.7$ & $92.2 \pm 2.1$ & $91.7 \pm 1.5$ & $92.2 \pm 1.8$ & n.s. \\
\hline $\mathrm{SpO}_{2}$ \%nadir & $84.9 \pm 6.1$ & $78.4 \pm 9.2$ & $78.6 \pm 5.8$ & $80.2 \pm 5.6$ & $80.3 \pm 7.7$ & 0.05 \\
\hline Mean amplitude \% & $3.6 \pm 0.4$ & $4.2 \pm 0.9$ & $4.2 \pm 1.1$ & $4.2 \pm 0.8$ & $4.1 \pm 0.9$ & n.s. \\
\hline ODI & $5.6 \pm 2.9$ & $22.3 \pm 13.3$ & $29.4 \pm 15$ & $26.9 \pm 16.8$ & $20.7 \pm 15.3$ & $<0.001$ \\
\hline$T_{90 \%}$ & $8.2 \pm 19.4$ & $14.5 \pm 16.2$ & $12.6 \pm 16.3$ & $13.7 \pm 15.7$ & $12.6 \pm 16.6$ & n.s. \\
\hline
\end{tabular}

Note: Data are presented as mean \pm SD.

Abbreviations: AHI, Apnea-Hypopnea Index; AHlo, obstructive AHI; AHlc, central AHI; MCA, mean duration of central apnea; MOA, mean duration of obstructive apnea; Mean $\mathrm{SpO}_{2}$, mean oxygen saturation value; $\mathrm{SpO}_{2}$, nadir minimum oxygen saturation value; Mean amplitude, mean amplitude of desaturation; ODI, oxygen desaturation index; $T_{90}$, recording time with $\mathrm{SpO}_{2}<90 \%$; No-SDB, no sleep-disordered breathing; d-OSA, dominant obstructive sleep apnea pattern; d-CSA, dominant central sleep apnea pattern; MP, mixed pattern.

groups were found in cardiopulmonary function or in the severity of sleep hypoxia. Patients with SDB (any type) had a higher body mass index (BMI) than those without SDB. No association was found between the pattern of SDB and gender, smoking, arterial hypertension, diabetes mellitus, COPD, and obesity. No differences were found between patients with infratentorial or supratentorial lesions in all sleep apnea severity indices. The ischemic damage was localized infratentorially in $33.3 \%$ of patients without SDB, in $18.5 \%$ of d-OSA, in $18.2 \%$ of d-CSA, and in $50 \%$ of patients with a mixed pattern $\left(\chi^{2}\right.$ n.s.).

Age was significantly positively correlated with AHI $(r=0.1, p<0.05)$ and obstructive AHI $(r=0.32, p<0.05)$, but not with central AHI. Similarly, age was negatively correlated with mean $\mathrm{SpO}_{2}(r=-0.3, p<0.05)$ and positively with oxygen desaturation index (ODI) $(r=0.3, p<0.05)$, but was not correlated with recording time with $\mathrm{SpO}_{2}<90 \%\left(T_{90}\right)$. BMI was positively correlated with AHI $(r=0.39, p=0.002)$ and obstructive AHI $(r=0.4, p=0.001)$, but not with central AHI. Finally, AHI and AHIo, but not central AHI, were significantly correlated with forced vital capacity (FVC) $(r=-0.31$ and $-0.35, p<0.05)$.

\section{Autonomic Data}

Neurovegetative data according to SDB pattern and presence/absence of arterial hypertension are reported in Table 3 . We found a statistically significantly difference between groups for baroreflex gain as assessed by index alpha BRS and alpha M, accompanied by a clear sympathetic activation in the d-OSA group, independently of the presence of arterial hypertension; a similar trend was found for ANSI, which, however, 
Table 3 Neurovegetative Data Categorized According to SDB Pattern and Presence/Absence of Arterial Hypertension at Baseline

\begin{tabular}{|c|c|c|c|c|c|c|}
\hline & & No-SDB & d-OSA & d-CSA & MP & $p$ \\
\hline & \multicolumn{6}{|c|}{ Hypertension } \\
\hline BRS & $\begin{array}{l}\text { No } \\
\text { Yes }\end{array}$ & $\begin{array}{l}10.8 \pm 7.8 \\
8.3 \pm 6.1\end{array}$ & $\begin{array}{l}8.4 \pm 3.7 \\
5.8 \pm 3.9\end{array}$ & $\begin{array}{l}25.1 \pm 19.9^{\circ} \\
9.4 \pm 6.9^{\circ}\end{array}$ & $\begin{array}{l}8.1 \pm 3 \\
5.9 \pm 3.5\end{array}$ & $<0.01$ \\
\hline ANSI & $\begin{array}{l}\text { No } \\
\text { Yes }\end{array}$ & $\begin{array}{l}36.9 \pm 30.9 \\
41.2 \pm 25\end{array}$ & $\begin{array}{l}48.4 \pm 33.1 \\
41.9 \pm 31.7\end{array}$ & $\begin{array}{l}87.8 \pm 2.8 \\
53.8 \pm 37.5\end{array}$ & $\begin{array}{l}47.4 \pm 41.7 \\
39.4 \pm 29.6\end{array}$ & n.s. \\
\hline Alpha M & $\begin{array}{l}\text { No } \\
\text { Yes }\end{array}$ & $\begin{array}{l}15 \pm 7.1 \\
8 \pm 5.2\end{array}$ & $\begin{array}{l}10.3 \pm 4.4 \\
10.8 \pm 6.9\end{array}$ & $\begin{array}{l}32.8 \pm 19.2^{*} \\
9.4 \pm 5.3^{*}\end{array}$ & $\begin{array}{l}7.7 \pm 2.8 \\
8.7 \pm 3\end{array}$ & $<0.01$ \\
\hline HR (beats/min) & $\begin{array}{l}\text { No } \\
\text { Yes }\end{array}$ & $\begin{array}{l}73 \pm 5.4 \\
65.6 \pm 12.1\end{array}$ & $\begin{array}{l}65.7 \pm 11 \\
66.6 \pm 11.4\end{array}$ & $\begin{array}{l}50 \pm 5.7 \\
62.8 \pm 13.6\end{array}$ & $\begin{array}{l}68.9 \pm 15.5 \\
66.3 \pm 8.9\end{array}$ & n.s. \\
\hline RR & $\begin{array}{l}\text { No } \\
\text { Yes }\end{array}$ & $\begin{array}{l}825 \pm 58 \\
943.5 \pm 180.5\end{array}$ & $\begin{array}{l}937.5 \pm 162 \\
926 \pm 161\end{array}$ & $\begin{array}{l}1208.4 \pm 137.3 \\
992.5 \pm 189\end{array}$ & $\begin{array}{l}905.6 \pm 198.2 \\
919.5 \pm 127.6\end{array}$ & n.s. \\
\hline RR LF/HF & $\begin{array}{l}\text { No } \\
\text { Yes }\end{array}$ & $\begin{array}{l}2.4 \pm 3.3 \\
2.1 \pm 2.8\end{array}$ & $\begin{array}{l}2.1 \pm 3 \\
3.9 \pm 4.6\end{array}$ & $\begin{array}{l}0.86 \pm 0.1 \\
3.4 \pm 7.5\end{array}$ & $\begin{array}{l}2.6 \pm 3.4 \\
4.7 \pm 3.9\end{array}$ & n.s. \\
\hline
\end{tabular}

Notes: Data are presented as mean \pm SD. ${ }^{\circ}$ and $*$ Intragroup post-hoc analysis.

Abbreviations: SDB, sleep-disordered breathing; BRS, time domain baroreflex sensitivity; ANSI, Autonomic Nervous System Index; Alpha M, frequency domain baroreflex gain; HR, heart rate; RR, RR interval; LF/HF, ratio of low frequency/high frequency; RR, R-R interval variability spectral power; No-SDB, no sleep-disordered breathing; $\mathrm{d}$-OSA, dominant obstructive sleep apnea pattern; d-CSA, dominant central sleep apnea pattern; MP, mixed pattern.

did not reach the significance level. Of interest, opposite results were found for d-CSA patients without arterial hypertension. Patients with a d-CSA pattern without arterial hypertension showed a significant increase in both BRS and index alpha, suggesting a hyperactivity of the parasympathetic branch of the autonomic system or a suppression of the sympathetic part.
Moreover, patients with normal ANSI showed higher central AHI (13.5 \pm 14.8 vs $5.2 \pm 7.8 ; p=0.009)$. A significant correlation was found between ANSI and central AHI ( $r=0.37, p=0.006)$ but not for obstructive AHI $(r=-0.08$, $p=$ n.s.). Similarly, the site of stroke seems to influence the baroreflex: BRS was higher in patients with infratentorial stroke (ANOVA $p=0.0007$ ), particularly in those without arterial hypertension (Table 4).

Table 4 Neurovegetative Data Categorized According to SDB Pattern and Site of Ischemic Stroke at Baseline

\begin{tabular}{|c|c|c|c|c|c|c|}
\hline & & No-SDB & d-OSA & d-CSA & MP & $p$ \\
\hline & \multicolumn{6}{|l|}{ Site } \\
\hline BRS & $\begin{array}{l}\text { Supra } \\
\text { Infra }\end{array}$ & $\begin{array}{l}9.4 \pm 7.8 \\
8.2 \pm 3.3\end{array}$ & $\begin{array}{l}6.7 \pm 3.9 \\
6 \pm 4.8\end{array}$ & $\begin{array}{l}8.5 \pm 6.1^{\circ} \\
29 \pm 14.5^{\circ}\end{array}$ & $\begin{array}{l}7.5 \pm 3.6 \\
6.7 \pm 3.3\end{array}$ & $<0.001$ \\
\hline ANSI & $\begin{array}{l}\text { Supra } \\
\text { Infra }\end{array}$ & $\begin{array}{l}33.5 \pm 18.9 \\
51.7 \pm 33.3\end{array}$ & $\begin{array}{l}44.1 \pm 33 \\
41.9 \pm 27.8\end{array}$ & $\begin{array}{l}54.8 \pm 38.3 \\
83.2 \pm 9.3\end{array}$ & $\begin{array}{l}29.3 \pm 21.2 \\
53.7 \pm 38.9\end{array}$ & n.s. \\
\hline $\begin{array}{l}\text { Alpha M } \\
\text { AHI }\end{array}$ & $\begin{array}{l}\text { Supra } \\
\text { Infra } \\
\text { Supra } \\
\text { Infra }\end{array}$ & $\begin{array}{l}9.9 \pm 7.1 \\
9.6 \pm 5.5 \\
5.6 \pm 2.3 \\
4.5 \pm 1.3\end{array}$ & $\begin{array}{l}10.8 \pm 5.1 \\
10.3 \pm 10.2 \\
24.4 \pm 15.8 \\
14.8 \pm 5\end{array}$ & $\begin{array}{l}9.8 \pm 6^{*} \\
30.6 \pm 22.2^{*} \\
36 \pm 14.4 \\
13.8 \pm 0.6\end{array}$ & $\begin{array}{l}8.1 \pm 2.9 \\
8.4 \pm 3 \\
29 \pm 16.5 \\
27 \pm 18.6\end{array}$ & $\begin{array}{l}0.004 \\
<0.001\end{array}$ \\
\hline AHlo & $\begin{array}{l}\text { Supra } \\
\text { Infra }\end{array}$ & $\begin{array}{l}2.7 \pm 1.2 \\
2.8 \pm 1.9\end{array}$ & $\begin{array}{l}22.7 \pm 16.3 \\
12.8 \pm 4.4\end{array}$ & $\begin{array}{l}5.7 \pm 4.2 \\
2.4 \pm 1.2\end{array}$ & $\begin{array}{l}13.7 \pm 7.5 \\
|4.9 \pm| 2.5\end{array}$ & $<0.001$ \\
\hline AHIc & $\begin{array}{l}\text { Supra } \\
\text { Infra }\end{array}$ & $\begin{array}{l}2.7 \pm 2.3 \\
1.7 \pm 1.3\end{array}$ & $\begin{array}{l}2.5 \pm 3.1 \\
2 \pm 2.2\end{array}$ & $\begin{array}{l}32.1 \pm 13.8 \\
11.2 \pm 0.8\end{array}$ & $\begin{array}{l}15.1 \pm 9.6 \\
\mid 1.7 \pm 7.1\end{array}$ & $<0.001$ \\
\hline
\end{tabular}

Note: Data are presented as mean $\pm \mathrm{SD} .^{\circ}$ and $*$ Intragroup post-hoc analysis.

Abbreviations: SDB, sleep-disordered breathing; BRS, time domain baroreflex sensitivity; ANSI, Autonomic Nervous System Index; Alpha M, frequency domain baroreflex gain; AHI, ApnEa-Hypopnea Index; AHlo, obstructive AHI; AHlc, central AHI; No-SDB, no sleep-disordered breathing; d-OSA, dominant obstructive sleep apnea pattern; d-CSA, dominant central sleep apnea pattern; MP, mixed pattern. 
Table 5 Sleep Data at Follow-Up Categorized According to Baseline SDB Pattern

\begin{tabular}{|c|c|c|c|c|c|c|}
\hline & No-SDB $(n=7)$ & d-OSA $(n=37)$ & d-CSA $(n=4)$ & $M P(n=12)$ & Total $(n=60)$ & $p$ \\
\hline Age (years) & $58.3 \pm 8$ & $62.1 \pm 9.7$ & $62 \pm 7.7$ & $59.4 \pm 11.8$ & $60.7 \pm 9.4$ & n.s. \\
\hline BMI $\left(\mathrm{kg} / \mathrm{m}^{2}\right)$ & $23.6 \pm 3.5$ & $27.7 \pm 4.8$ & $27.2 \pm 2.2$ & $27.5 \pm 3.8$ & $26.7 \pm 4.2$ & 0.02 \\
\hline ESS & & & & & & n.s. \\
\hline $\mathrm{AHI}$ & $7.2 \pm 3.9$ & $21.1 \pm 16.3$ & $25.1 \pm 15$ & $15.7 \pm 11$ & $17.7 \pm 14.3$ & $<0.001$ \\
\hline AHI supine & $17.6 \pm 11$ & $37 \pm 28.7$ & $36.1 \pm 22.5$ & $28 \pm 15.5$ & $30.5 \pm 22.7$ & n.s. \\
\hline AHlo & $5.2 \pm 3.8$ & $16.8 \pm 11.3$ & $|4.7 \pm| 4 . \mid$ & $11.2 \pm 10.3$ & $12.4 \pm 1 \mid .1$ & 0.02 \\
\hline AHIc & $2 \pm 2.6$ & $1.6 \pm 1.5$ & $10.3 \pm 9$ & $4.3 \pm 2.9$ & $3.9 \pm 5.2$ & $<0.0001$ \\
\hline MCA s & $13.5 \pm 2.6$ & $15 \pm 3.4$ & $17.6 \pm 3.6$ & $14.9 \pm 2.7$ & $15.1 \pm 2.7$ & n.s. \\
\hline MOA s & $12.7 \pm 10.1$ & $19.4 \pm 4.5$ & $20 \pm 3.9$ & $16 \pm 6.7$ & $17.1 \pm 7.1$ & 0.02 \\
\hline Mean $\mathrm{SpO}_{2} \%$ & $92.7 \pm 1.4$ & $92.1 \pm 1.8$ & $91.4 \pm 1.3$ & $91.7 \pm 1.9$ & $92 \pm 1.7$ & n.s. \\
\hline $\mathrm{SpO}_{2}$ nadir \% & $85.8 \pm 5.5$ & $77.5 \pm 9.9$ & $80.4 \pm 5.3$ & $82.2 \pm 5.9$ & $80.8 \pm 7.9$ & 0.01 \\
\hline ODI & $7.5 \pm 4.3$ & $20.7 \pm 14.9$ & $25.4 \pm 14.2$ & $16.3 \pm 11.1$ & $17.7 \pm 13.6$ & $<0.01$ \\
\hline$T_{90} \%$ & $4.1 \pm 8.7$ & $12.5 \pm 13.4$ & $17.5 \pm 18.8$ & $15.5 \pm 21.8$ & $12.1 \pm 16.2$ & n.s. \\
\hline
\end{tabular}

Note: Data are presented as mean \pm SD unless otherwise indicated.

Abbreviations: SDB, sleep-disordered breathing; BMI, body mass index; ESS, Epworth Sleepiness Score; AHI, ApnEa-Hypopnea Index; AHlo, obstructive AHI; AHIc,

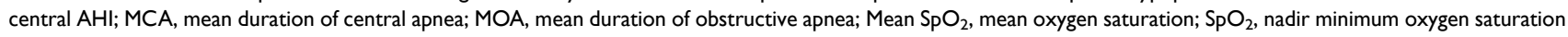
value; ODI, oxygen desaturation index; $T_{90}$, recording time with $\mathrm{SpO}_{2}<90 \%$; No-SDB, no sleep-disordered breathing; d-OSA, dominant obstructive sleep apnea pattern; d-CSA, dominant central sleep apnea pattern; MP, mixed pattern.

\section{Chronic Phase}

\section{Clinical and Sleep Data}

Seven patients (11.7\%) had No-SDB, $37(61.7 \%)$ had a d-OSA pattern, four $(6.6 \%)$ had a d-CSA pattern, and $12(20 \%)$ showed a mixed pattern (MP). Overall, an AHI $>10$ was found in 41 patients $(68.3 \%)$ and an $\mathrm{AHI}>30$ was found in nine patients $(15 \%)$. Cheyne-Stokes respiration (CSR) was found in $18.2 \%$ of patients: in $3.2 \%$ of patients with predominant OSA, in $75 \%$ of patients with predominant CSA, and in $50 \%$ of patients with a mixed pattern $\left(\chi^{2}<0.001\right)$.

Sleep data are separated for each subgroup of patients classified according to SDB pattern in the acute phase (Table 5): the highest value of AHI was found in patients with a d-CSA pattern.

Global AHI was slightly improved $(22.2 \pm 16.9$ at baseline vs $17.7 \pm 14.3$ at follow-up, $p=0.005$ ). The opposite trend was found for obstructive AHI, which was unchanged ( $12 \pm 11.6$ vs $11.8 \pm 10.2$, respectively; $p=$ n.s.), and for central AHI, that was significantly reduced (9.4 \pm 12 vs $4 \pm 5.3$, respectively; $p<0.0001$ ).

\section{Autonomic Data}

Autonomic data separated for each subgroup of patients classified according to SDB pattern in the chronic phase are reported in Table 6.

Overall, we found higher values of global, central, and obstructive AHI in patients with supratentorial lesions, regardless of the nature of the SDB pattern (ANCOVA
$<0.05)$. A similar pattern was found for ODI $(20.1 \pm 15.3$ in supratentorial vs $12.1 \pm 5.2$ in infratentorial, $p<0.05$ ).

We found higher values of BRS in patients with d-CSA without hypertension in comparison to those with hypertension $(27.2 \pm 0.01$ vs $5.9 \pm 0.2, p<0.001)$. Moreover, in an ANCOVA adjusted for age, we found higher levels of BRS in patients with infratentorial lesion in comparison to those with supratentorial lesion. This difference disappeared in patients with concomitant arterial hypertension.

\section{Changes from Acute to Chronic Phase}

Smaller variations in AHI were found in the no-SDB and d-OSA groups $(\triangle \mathrm{AHI} 2.1 \pm 4.1$ and $-2.8 \pm 11.6$, respectively) in comparison with d-CSA and MP ( $\triangle \mathrm{AHI}-6.9$ \pm 15.1 and $-12.5 \pm 13.1$, respectively) (ANOVA $p=0.01$ ). Differences between groups were stronger in obstructive AHI (ANOVA $p=0.003$ ), with a significant increase in the d-CSA group ( $\triangle$ AHIo $11.4 \pm 14.6$ ) versus a more stable pattern in the other groups $(2.5 \pm 3.7$ in no-SDB; -2.3 \pm 11.2 in d-OSA; $-3.1 \pm 9.8$ in MP).

We observed a marked change in the relative distribution of SDB patterns $\left(\chi^{2}=29.6 ; p<0.0001\right)$, as shown in Table 7. Changes were very frequent in d-CSA and MP patients, while those with a d-OSA showed a very stable pattern of SDB. OSA became the most frequent pattern of SDB, seen in $38.3 \%$ of patients at baseline and $61.7 \%$ of patients at follow-up. 
Table 6 Sleep and Autonomic Data at Follow-Up for Each Group According to Site of Ischemic Stroke and SDB Pattern Observed in the Chronic Phase

\begin{tabular}{|c|c|c|c|c|c|c|}
\hline & & No-SDB & d-OSA & d-CSA & MP & $p$ \\
\hline & \multicolumn{6}{|l|}{ Side } \\
\hline BRS & $\begin{array}{l}\text { Supra } \\
\text { Infra }\end{array}$ & $\begin{array}{l}11.1 \pm 9.4 \\
13.2 \pm 5.6\end{array}$ & $\begin{array}{l}11.2 \pm 10.6 \\
9.2 \pm 9.5\end{array}$ & $\begin{array}{l}5.9 \pm 0.3 \\
27.2 \pm 0.01\end{array}$ & $\begin{array}{l}8.1 \pm 5.1 \\
61.7 \pm 105\end{array}$ & n.s. \\
\hline Alpha M & $\begin{array}{l}\text { Supra } \\
\text { Infra }\end{array}$ & $\begin{array}{l}8.6 \pm 5.2 \\
19.1 \pm 16.7\end{array}$ & $\begin{array}{l}13.9 \pm 15.1 \\
7.7 \pm 6\end{array}$ & $\begin{array}{l}8 \pm 2.8 \\
25.6 \pm 0.2\end{array}$ & $\begin{array}{l}6.8 \pm 4.2 \\
18.5 \pm 13\end{array}$ & n.s. \\
\hline $\mathrm{AHI}$ & $\begin{array}{l}\text { Supra } \\
\text { Infra }\end{array}$ & $\begin{array}{l}3.4 \pm 1.7 \\
3.2 \pm 1.8\end{array}$ & $\begin{array}{l}24.4 \pm 17.3 \\
12.6 \pm 3.3\end{array}$ & $\begin{array}{l}24.8 \pm 17.6 \\
7.5 \pm 0.1\end{array}$ & $\begin{array}{l}15.9 \pm 8.6 \\
14.9 \pm 4.9\end{array}$ & 0.02 \\
\hline AHlo & $\begin{array}{l}\text { Supra } \\
\text { Infra }\end{array}$ & $\begin{array}{l}2.4 \pm 1.3 \\
1 \pm 0.9\end{array}$ & $\begin{array}{l}19.5 \pm 13.5 \\
11.3 \pm 3.1\end{array}$ & $\begin{array}{l}5.5 \pm 6.5 \\
1 \pm 0.05\end{array}$ & $\begin{array}{l}9.3 \pm 5.5 \\
7.6 \pm 3.6\end{array}$ & 0.03 \\
\hline AHIc & $\begin{array}{l}\text { Supra } \\
\text { Infra }\end{array}$ & $\begin{array}{l}0.9 \pm 0.6 \\
2.1 \pm 2.7\end{array}$ & $\begin{array}{l}2.2 \pm 2.7 \\
1.2 \pm 1.1\end{array}$ & $\begin{array}{l}\mid 9.3 \pm 11.1 \\
6.5 \pm 0.05\end{array}$ & $\begin{array}{l}6.7 \pm 3.5 \\
6.7 \pm 1.9\end{array}$ & $<0.001$ \\
\hline
\end{tabular}

Note: Data are presented as mean \pm SD.

Abbreviations: SDB, sleep-disordered breathing; BRS, time domain baroreflex sensitivity; Alpha M, frequency domain baroreflex gain; AHI, Apnea-Hypopnea Index; AHlo, obstructive AHI; AHIc, central AHI; No-SDB, no sleep-disordered breathing; d-OSA, dominant obstructive sleep apnea pattern; d-CSA, dominant central sleep apnea pattern; MP, mixed pattern; Supra, supratentorial; Infra, infratentorial.

Figure 2 reports the changes in the AHI between baseline and follow-up in the four different subgroups classified according to SDB pattern at baseline (MANOVA 3.8; $p=0.01$ ), separately for global (A), obstructive (B), and central (C). The greatest decrease in AHI was found in the MP groups (post-hoc $p<0.01$ ), while the greatest increase in AHIo was found in the d-CSA groups (posthoc $p<0.05$ ). The AHIc was very stable in the No-SDB and d-OSA groups, and significantly reduced in the d-CSA and MP groups (post-hoc $p<0.0001$ ).

Overall, no differences were found for BRS and alpha $\mathrm{M}$ data between baseline and follow-up according to the baseline or follow-up SDB pattern and presence/absence of arterial hypertension. In contrast, the modification of BRS over time was influenced by the site of the lesion and by the SDB pattern in the acute phase (Figure 3;

Table 7 Individual Changes in SDB Patterns Between Baseline and Follow-Up

\begin{tabular}{|c|c|c|c|c|c|c|}
\hline & Follow- & & & & & \\
\hline \multirow[t]{6}{*}{ Baseline } & & No-SDB & d-OSA & d-CSA & MP & Totals \\
\hline & No-SDB & 5 & 6 & 1 & I & 13 \\
\hline & d-OSA & 1 & 21 & 0 & 1 & 23 \\
\hline & d-CSA & 1 & 4 & 2 & 4 & 11 \\
\hline & MP & 0 & 6 & I & 6 & 13 \\
\hline & Totals & 7 & 37 & 4 & 12 & 60 \\
\hline
\end{tabular}

Abbreviations: SDB, sleep-disordered breathing; No-SDB, no sleep-disordered breathing; d-OSA, dominant obstructive sleep apnea pattern; d-CSA, dominant central sleep apnea pattern; MP, mixed pattern.
MANOVA $p=0.005$ ). The trend of ANSI was only influenced by the site of lesion (Figure 4; MANOVA $p=0.04$ ). Patients with normal ANSI at follow-up showed higher central AHI ( $5 \pm 7.2$ vs $2.4 \pm 2.5$, as observed in the acute phase), close to reaching the significance level $(p=0.07)$.

\section{Discussion}

The main findings of the present study were: 1) a high prevalence and variability of SDB in the acute phase of cerebral ischemic events that persisted after 3 months; and 2) a different pattern of autonomic activation in obstructive versus central SDB and in supratentorial versus infratentorial lesions.

Previous meta-analyses reported a high variability in the prevalence and heterogeneity of SDB in patients following a transient ischemic attack/stroke. Several factors were hypothesized to explain this heterogeneity. The technical approach to the sleep study was considered the first source of variability: polysomnography (PSG), 8-channel respiratory polygraphy, simplified respiratory monitoring without the possibility to classify the nature of respiratory events, and auto-CPAP devices have been used in previous studies. ${ }^{23}$ Similarly, the different criteria used in the definition and classification of hypopnea (including the different levels of associated $\mathrm{SpO}_{2}$ drops) is another important source of variability. As a consequence, the dominant pattern of SDB in each patient was attributed according to the apnea index. However, looking at the largest studies (number of patients $>100$ ), we can easily recognize that 

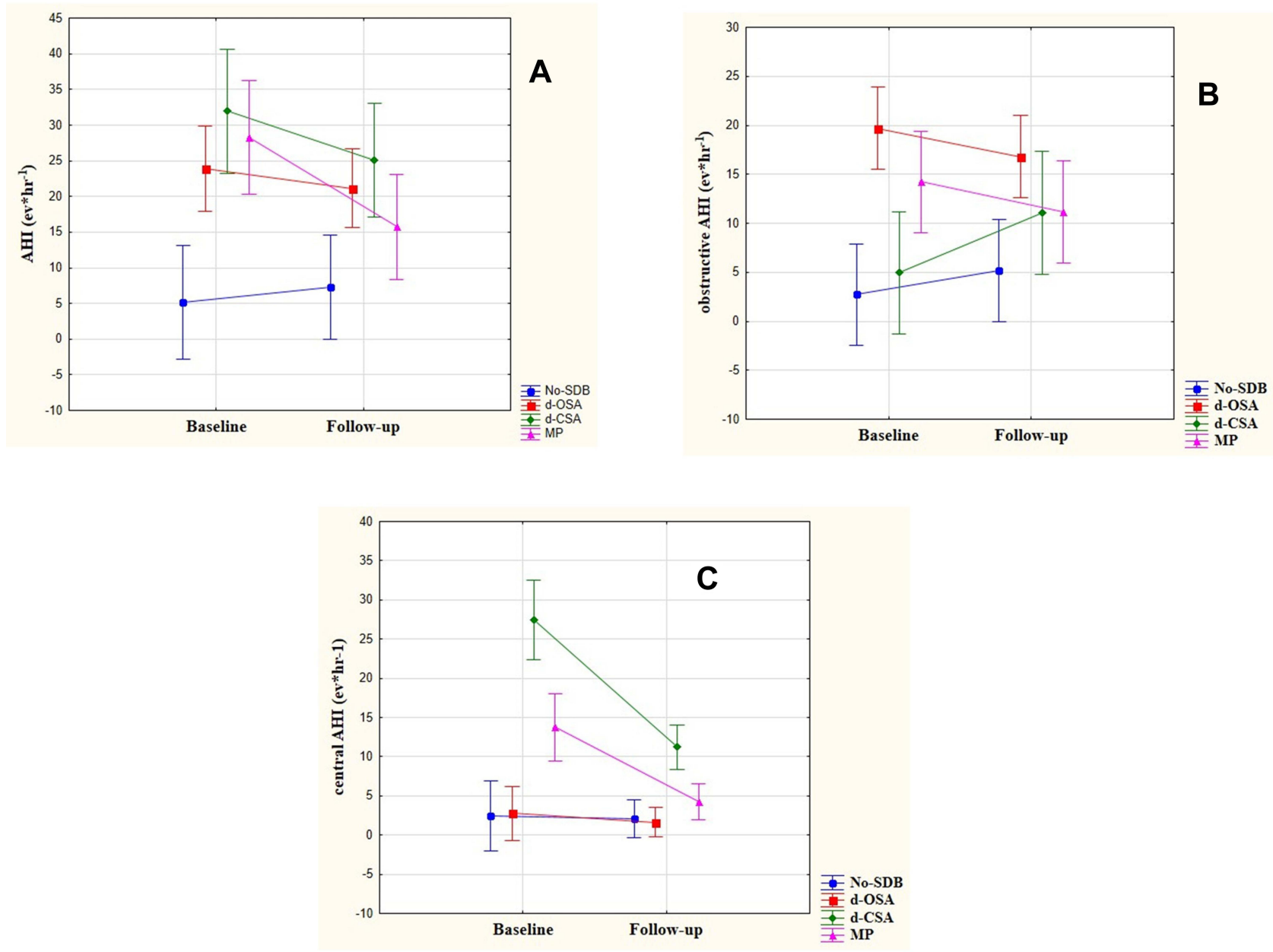

Figure 2 Changes in global (A), obstructive (B) and central AHI (C) between acute and chronic phases in the four groups of patients, separately for SDB pattern at baseline.

the most prevalent respiratory events were hypopneas. ${ }^{23}$ According to the American Academy of Sleep Medicine criteria, we have classified all the respiratory events, including hypopneas, in order to define for each patient the prevalent pattern of SDB. We are aware that the $70 \%$ threshold that we have chosen to classify patients is arbitrary, but we preferred to adopt a higher cut-off than usual to be sure to identify the "true" central pattern. By using this threshold, the results allowed a clear physiological differentiation of each group of patients. Indeed, using the usual $50 \%$ threshold to classify the patients, we found a clear overlap between patients with prevalent OSA and CSA. These results are available as supplemental material in Table E1 and Figures E1-E3.

The prevalence of SDB in the present study was very high, in both the acute and chronic phases. Differently from previous studies, we did not find a significantly spontaneous improvement over time..$^{1,3,23,24}$ In particular, only $38 \%$ of patients classified as no-SDB at baseline still had the same pattern at follow-up: $46.1 \%$ developed a d-OSA and the remaining patients a d-CSA or mixed pattern.

OSA remains the most frequent SDB type, especially in the chronic phase, but with a lower prevalence than previously reported. ${ }^{4}$ In contrast, we found a higher prevalence of CSA or mixed pattern: the prevalence of CSA in the acute phase has been estimated to be $7 \%$ in a recent meta-analysis ${ }^{23}$ and as $2.2 \%$ in another study. ${ }^{5}$ The mixed pattern was not previously detected owing to the absence of specific criteria to discriminate between obstructive and central hypopneas. Central events did not correlate with common anthropometric determinants of OSA such as age, BMI, and lung volumes, suggesting a different physiological mechanism. Indeed, modifications in SDB pattern and severity were found between baseline and follow-up evaluation, especially in patients with a baseline d-CSA or 


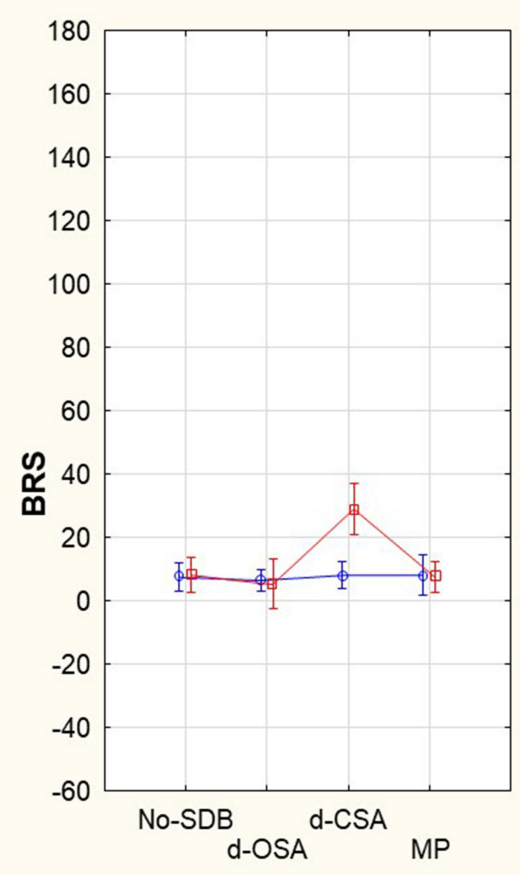

Acute

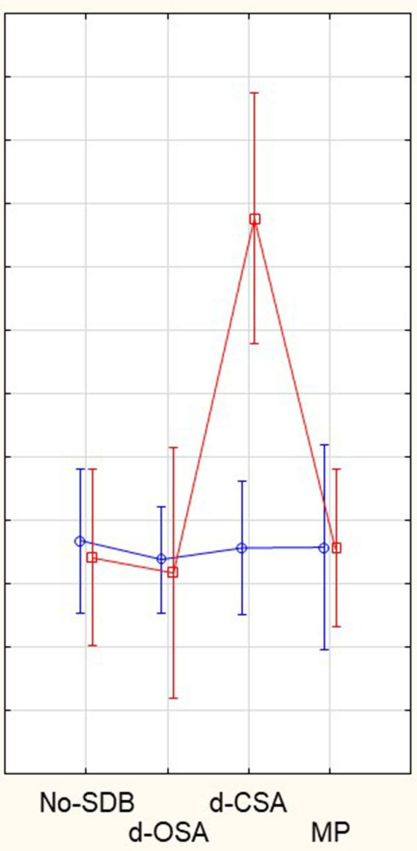

Chronic
Supra-

Infra-tentorial

Figure 3 Modification over time of BRS evaluated according to the site of lesion and the pattern of SDB.

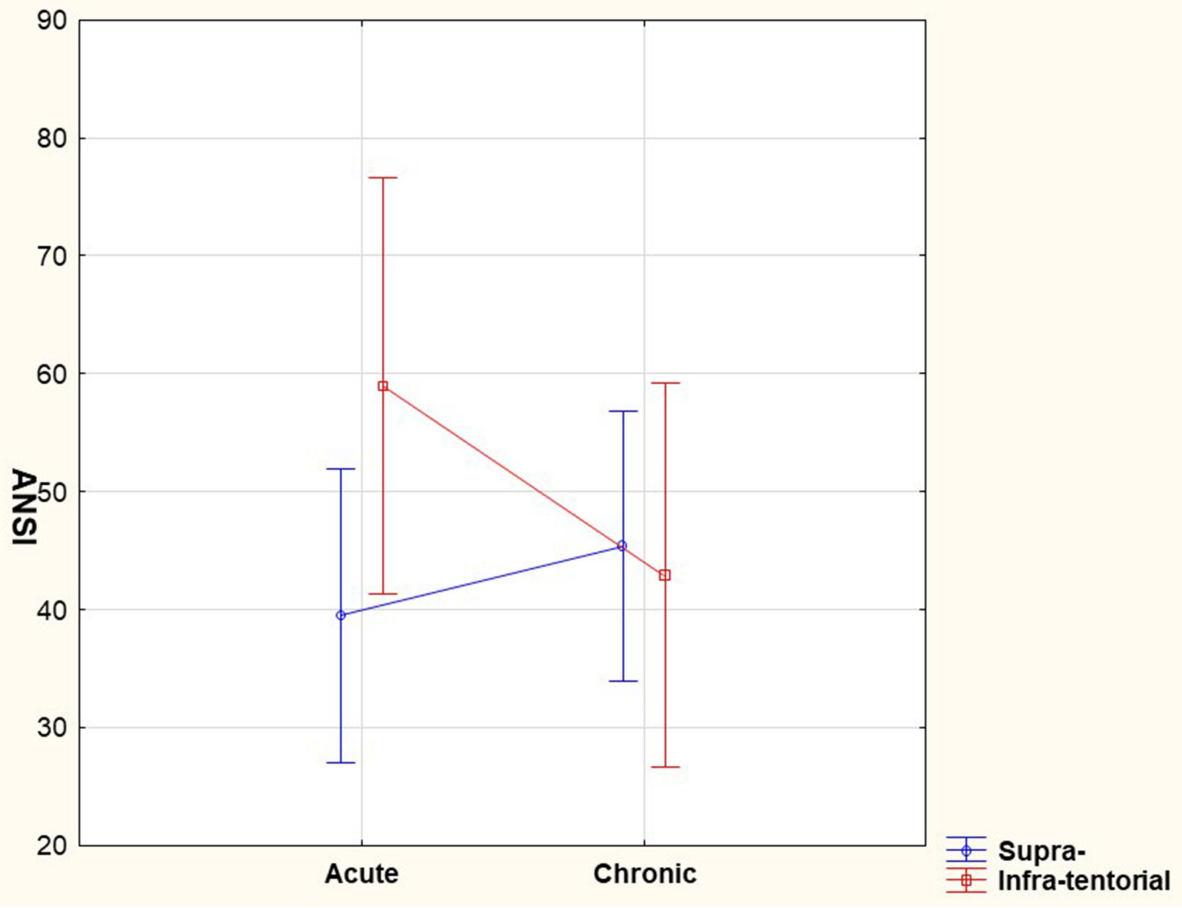

Figure 4 Trend of ANSI between acute and chronic phases according to site of ischemic lesion.

mixed pattern. Most of these developed a d-OSA pattern at follow-up, suggesting the pre-existence of OSA before the stroke.
The presence of sympathetic overactivity in OSA patients was recognized many years ago. ${ }^{25}$ Similar findings were found in the present study in the d-OSA group 
and/or in patients with arterial hypertension. It is well known that repetitive episodes of intermittent hypoxia promote hyperventilation, vasoconstriction to redistribute blood flow to vital organs, and bradycardia to reduce myocardial oxygen demand. ${ }^{26}$ Impairment in baroreceptor sensitivity has been reported in patients with acute ischemic stroke and has been associated with increased long-term mortality. ${ }^{13}$ However, the presence of arterial hypertension and sleep apnea was not previously considered. Similar data were reported by Sykora et $\mathrm{al}^{15}$ for patients with acute intracerebral hemorrhage and more recently by Webb et al. ${ }^{14}$

The pathophysiological mechanisms of reduced baroreceptor sensitivity in patients with stroke are not known. Several hypotheses have been suggested: 1) the site of the lesion, ${ }^{9,10,26}$ 2) the coexistence of arterial hypertension, ${ }^{27} 3$ ) the presence of bilateral carotid atherosclerosis, ${ }^{12,28}$ and 4) the presence of SDB. ${ }^{29,30}$ Accordingly, in the present study, three different factors were individually and mutually associated with reduced baroreflex gain, in the acute as well as in the chronic phase: 1) arterial hypertension, 2) d-OSA pattern, and 3) supratentorial site of lesion. Our results concur with those published by Taylor et al, where a thinning of the left dorsal posterior insula (ldpIC), the vasodepressor region, was reported in patients with moderate to severe OSA: the severity of nocturnal hypoxia was inversely correlated with the thickness of the ldpIC. ${ }^{30}$ In the same study, the authors found an increase in gray matter thickness or density in the left mid-cingulate cortex in the region of the left posterior thalamus, probably related to a chronically augmented chemoreceptor input due to repetitive episodes of asphyxia and intermittent hypoxia. ${ }^{30,31}$ On the other hand, Spicuzza et al reported a different autonomic heart-rate modulation during obstructive versus central apneas in patients with sleep apnea: apart from obstructive events, during central apnea episodes, the respiratory component of R-R interval variability is nearly absent during the apneic phase and recovers with the resumption of ventilation. ${ }^{32}$ They concluded that the autonomic changes, initiated by an obstructive event, may last into the post-apneic phase, whereas the changes induced by the central events passively reflect the changes in ventilation.

Baroreflex sensitivity is usually reduced during exercise in healthy individuals, and it is reduced in the upright versus supine position. ${ }^{33,34}$ The latter condition is characterized by predominant sympathetic modulation; the former implies possible suppression of vagal activity. ${ }^{35-38}$ Therefore, it is tempting to suggest that the autonomic changes observed in the present study may be related to a reduction, if not a suppression, of autonomic modulation of the heart in stroke-related SDB.

Up to now, studies designed to assess the mutual relationship between lesion location and type or severity of SDB have given mixed and inconclusive results. ${ }^{8} \mathrm{We}$ found a solid relationship between a d-CSA pattern and an infratentorial lesion. These patients showed higher indices of baroreflex gain and ANSI values, and changes in baroreflex over time were influenced by the site of lesion and by the pattern of SDB: BRS improved only in d-CSA patients with an infratentorial lesion.

The design of the present study did not permit the identification of the pathophysiological mechanisms of this finding. In the acute phase after the stroke, all the circuits that regulate the breathing pattern as well as autonomic outflow may be blunted. ${ }^{30}$ Transitory loss of information from peripheral chemoreceptors or lung receptors, or a loss of connections inside the central autonomic network may explain 1) the shift of central autonomic regulation to an inhibitory prevalence in patients with d-CSA without arterial hypertension and 2) the reduced ventilatory drive that we indirectly observed in these patients: baseline carbon dioxide was higher in patients with d-CSA or mixed pattern in comparison to that with d-OSA. On the other hand, it has been demonstrated that slow breathing enhances baroreflex sensitivity without inducing hyperventilation. ${ }^{39}$ Similarly, LorenziFilho et al demonstrated that periodic breathing with central apneas entrains blood pressure and heart rate and increases the magnitude of their oscillations in healthy subjects. $^{40}$

\section{Conclusion}

The present results suggest a down-regulation of autonomic activity, possibly related to reduced vagal modulation, that may sustain the recovery after stroke, or a transitory disconnection from the cortical node that participates in the regulation of sympathetic outflow, altering the excitatory-inhibitory balance.

The enrollment of relatively young patients with mild to moderate stroke severity gave us the possibility to explore some physiological insights that would otherwise not be detectable in patients with severe lesions. However, larger multicentric studies, ideally extended to patients with hemorrhagic and large and severe brain ischemic 
damage, are necessary to confirm the main findings of the present study: preserved baroreflex sensitivity was found only in those patients with concomitant infratentorial lesion, d-CSA pattern and absence of peripheral arterial hypertension. Determining the exact physiological mechanisms that link these three factors should be aim of future investigations.

A clear limitation of this study is the arbitrariness of the cut-off that we chose to classify patients in the obstructive, central or mixed pattern. We chose to classify all respiratory events, apneas and hypopneas, according to the standard criteria and we identified a $70 \%$ cut-off as a threshold to discriminate the different respiratory patterns potentially expressing different underlying pathophysiological mechanisms. However, we recognize the need for a methodological study to define the future appropriate method for the classification of SDB patterns in specific categories of patients (ie, stroke, heart failure) where mixed patterns are very common.

Finally, the methods used did not allow us to explore a pre-existing form of SDB before stroke, and this is certainly a further limit of the present study.

\section{Ethics Statement}

Ethical approval of the study protocol was obtained from the Cantonal Ethics Committee Republic and Canton of Ticino (no. CE 2496). All participants gave written informed consent. This study was conducted in accordance with the Declaration of Helsinki.

\section{Acknowledgments}

We acknowledge Dr. Pierluigi Crivelli foundation, Cecilia Augusta foundation and ABREOC for the support offered to our research.

\section{Author Contributions}

Study design: AR, FF, MPag, MMan, GF, FE, CC, MMal, DL, MP. Data collection: AR, MMan, FE, MMal, MP. Data analysis and interpretation: AR, FF, DL, MPag, MMal, MMan, GF, MP. Literature search and generation of figures: AR, FF, MPag, MMan. Manuscript preparation: AR, FF, MPag, MMan, GF, FE, CC, MMal, DL and MP. All authors made substantial contributions to conception and design, acquisition of data, or analysis and interpretation of data; took part in drafting the article or revising it critically for important intellectual content; agreed to submit to the current journal; gave final approval of the version to be published; and agree to be accountable for all aspects of the work.

\section{Funding}

The study was supported by grants from ABREOC (Scientific Research Advisory Board of the Ente Ospedaliero Cantonale), Dr PierLuigi Crivelli Foundation, and Cecilia Augusta Foundation.

\section{Disclosure}

Dr Alessia Riglietti reports grants from ABREOC (Scientific Research Advisory Board of the Ente Ospedaliero Cantonale), Doctor PierLuigi Crivelli Foundation and Cecilia Augusta Foundation, during the conduct of the study. Dr Carlo W Cereda is a member of the iSchemaView Medical and Scientific Advisory Board, but this institution played no role in current research . Prof. Dr Marco Pons report grants from ABREOC, Dr Pieruigi Crivelli Foundation and Cecilia Augusta Foundation, during the conduct of the study. The authors have no other financial support or conflicts of interest to declare.

\section{References}

1. Bassetti CL. Sleep and stroke. Semin Neurol. 2005;25(1):19-31. doi:10.1055/s-2005-867073

2. Turkington PM, Bamford CR, Wanklyn P, et al. Prevalence and predictors of upper airway obstruction in the first 24 hours after acute stroke. Stroke. 2002;33(8):2037-2042. doi:10.1161/01. STR.0000023576.94311.27

3. Parra O, Arboix A, Beschich S, et al. Time course of sleep-related breathing disorders in first-ever stroke or transient ischemic attack. Am J Respir Crit Care Med. 2000;161(2):375-380. doi:10.1164/ ajrccm.161.2.9903139

4. Herman DM, Bassetti CL. Role of sleep-disordered breathing and sleep-wake disturbances for stroke and stroke recovery. Neurology. 2016;87(13):1407-1416. doi:10.1212/WNL.0000000000003037

5. Bravata DM, McClain V, Austin C, et al. Diagnosing and managing sleep apnoea in patients with chronic cerebrovascular disease: a randomized trial of a home-based strategy. Sleep Breath. 2017;21 (3):713-725. doi:10.1007/s11325-017-1494-5

6. Nopmaneejumruslers C, Kaneko Y, Hajek V, et al. Cheyne-Stokes respiration in stroke. Am J Respir Crit Care Med. 2005;171 (9):1048-1052. doi:10.1164/rccm.200411-1591OC

7. Siccoli M, Valko PO, Hermann DM, et al. Central periodic breathing during sleep in 74 patients with acute ischemic stroke-Neurogenic and cardiogenic factors. $J$ Neurol. 2008;255(11):1687-1692. doi:10.1007/s00415-008-0981-9

8. Steven D, Martins RT, Mucherjee S, et al. Post-stroke sleep-disordered breathing pathophysiology and therapy options. FrontSurg. 2018;5:9

9. Hilz MJ, Dutsch M, Perrine K, et al. Hemispheric influence on autonomic modulation and baroreflex sensitivity. AnnNeurol. 2001;49:575-584.

10. Robinson TG, James M, Youde J, et al. Cardiac baroreceptor sensitivity is impaired after acute stroke. Stroke. 1997;28(9):1671-1676. doi:10.1161/01.STR.28.9.1671

11. Eames PJ, Blake MJ, Dawson SL, et al. Dynamic cerebral autoregulation and beat to beat blood pressure control are impaired in acute ischemic stroke. J Neurol Neurosurg Psychiatry. 2002;72 (4):467-472. doi:10.1136/jnnp.72.4.467 
12. Nasr N, Pavy-le Traon A, Larrue V, et al. Baroreflex sensitivity is impaired in bilateral carotid atherosclerosis. Stroke. 2005;36 (9):1891-1895. doi:10.1161/01.STR.0000177890.30065.cb

13. Robinson TJ, Dawson SL, Eames PJ, et al. Cardiac baroreceptor sensitivity predicts long-term outcome after acute ischemic stroke. Stroke. 2003;34(3):705-712. doi:10.1161/01.STR.0000058493.94875.9F

14. Webb AJS, Mazzucco S, Li L, et al. Prognostic significance of blood pressure variability on beat-to-beat monitoring after transient ischemic attack and stroke. Stroke. 2018;49(1):62-67. doi:10.1161/ STROKEAHA.117.019107

15. Sykora M, Diedler J, Rupp A, et al. Impaired baroreflex sensitivity predicts outcome of acute intracerebral haemorrhage. CritCareMed. 2008;36:3074-3079.

16. Sykora M, Diedler J, Turcani P, et al. Baroreflex: a new therapeutic target in human stroke. Stroke. 2009;40(12):e678-e682. doi:10.1161/ STROKEAHA.109.565838

17. Vignatelli L, Plazzi G, Barbato A, et al. Italian version of the Epworth sleepiness scale: external validity. Neurol Sci. 2003;23 (6):295-300. doi:10.1007/s100720300004

18. American Academy of Sleep Medicine. International Classification of Sleep Disorders. 3rd ed. Dairen, IL; 2014.

19. Berry RB, Brooks R, Gamaldo CE, et al.; for the American Academy of Sleep Medicine. The AASM Manual for the Scoring of Sleep and Associated Events: Rules, Terminology and Technical Specifications, Version 2.1. Darien, Illinois: American Academy of Sleep Medicine; 2014. Available from: www.aasmnet.org. Accessed June 17, 2021.

20. Gibson GJ. Clinical Tests of Respiratory Function. 3rd ed. 2009, Hodder Arnold, CRC Press, Taylor and Francis group.

21. Sala R, Malacarne M, Solaro N, et al. A composite autonomic index as unitary metric for heart rate variability: a proof of concept. Eur J Clin Invest. 2017;47(3):241-249. doi:10.1111/eci.12730

22. Solaro N, Malacarne M, Pagani M, et al. Cardiac baroreflex, HRV, and statistics: an interdisciplinary approach in hypertension. Front Physiol. 2019;10:478. doi:10.3389/fphys.2019.00478

23. Johnson KG, Johnson DC. Frequency of sleep apnoea in stroke and TIA patients: a meta-analysis. J Clin Sleep Med. 2010;6(2):131-137. doi: $10.5664 /$ jcsm. 27760

24. Slonkova J, Bar M, Nilius P, et al.Spontaneous improvement in both obstructive sleep apnea and cognitive impairment after stroke. Sleep Med. 2017;32:137-142. doi:10.1016/j.sleep.2016.11.024

25. Somers VK, Dyken ME, Clary MP, et al. Sympathetic neural mechanisms in obstructive sleep apnoea. J Clin Invest. 1995;96 (4):1897-1904. doi:10.1172/JCI118235

26. Sykora M, Diedler J, Rupp A, et al. Impaired baroreceptors reflex sensitivity in acute stroke is associated with insular involvement, but not with carotid atherosclerosis. Stroke. 2009;40(3):737-742. doi:10.1161/STROKEAHA.108.519967

27. Johnson AK, Zhang Z, Clayton SC, et al. The roles of sensitization and neuroplasticity in the long-term regulation of blood pressure and hypertension. Am J Physiol Regul Integr Comp Physiol. 2015;309 (11):R1309-R1325. doi:10.1152/ajpregu.00037.2015
28. Rupprecht S, Hoyer D, Hagemann G, et al. Central sleep apnoea indicates autonomic dysfunction in asymptomatic carotid stenosis: a potential marker of cerebrovascular and cardiovascular risk. Sleep. 2010;33(3):327-333. doi:10.1093/sleep/33.3.327

29. Abboud F, Kumar R. Obstructive sleep apnoea and insight into mechanism of sympathetic overactivity. J Clin Invest. 2014;124 (4):1454-1457. doi:10.1172/JCI70420

30. Taylor KS, Millar PJ, Murai H, et al. Cortical autonomic network gray matter and sympathetic nerve activity in obstructive sleep apnoea. Sleep. 2018;41(2):1-10. doi:10.1093/sleep/zsx208

31. Oppenheimer SM, Gelb A, Girvin JP, et al. Cardiovascular effects of human insular cortex stimulation. Neurology. 1992;42(9):1727-1732. doi:10.1212/WNL.42.9.1727

32. Spicuzza L, Bernardi L, Calciati A, et al. Autonomic modulation of heart rate during obstructive versus central apnoeas in patients with sleep-disorder breathing. Am J Respir Crit Care Med. 2003;167 (6):902-910. doi:10.1164/rccm.200201-006OC

33. Iellamo F, Legramante JM, Raimondi G, et al. Baroreflex control of sinus node during dynamic exercise in humans: effects of central command and muscle reflexes. Am J Physiol Heart Circ Physiol. 1997;272:H1157-H1164.

34. Schwartz CE, Medow MS, Messer Z, et al. Spontaneous fluctuation indices of the cardiovagal baroreflex accurately measure the baroreflex sensitivity at the operating point during upright tilt. Am J Physiol Regul Integr Comp Physiol. 2013;304(12):R1107-R1113. doi:10.1152/ajpregu.00559.2012

35. Pagani M, Lombardi F, Guzzetti S, et al. Power spectral analysis of heart rate and arterial pressure variabilities as a marker of sympatho-vagal interaction in man and conscious dog. Circ Res. 1986;59(2):178-193. doi:10.1161/01.RES.59.2.178

36. Vybiral T, Bryg RJ, Maddens ME, et al. Effect of passive tilt on sympathetic and parasympathetic components of heart rate variability in normal subjects. Am $J$ Cardiol. 1989;63(15):1117-1120. doi:10.1016/0002-9149(89)90089-1

37. Bringard A, Adami A, Fagoni N, et al. Dynamics of arterial baroreflex resetting at exercise onset in humans. Eur Appl Physiol. 2017;117(4):619-630. doi:10.1007/s00421-017-3564-6

38. Fontolliet T, Pichot V, Bringard A, et al. Testing the vagal withdrawal hypothesis during light exercise under autonomic blockade: a heart rate variability study. J Appl Physiol. 2018;125(6):1804-1811. doi:10.1152/japplphysiol.00619.2018

39. Joseph CN, Porta C, Casucci G, et al. Slow breathing improves arterial baroreflex sensitivity and decreases blood pressure in essential hypertension. Hypertension. 2005;46(4):714-718. doi:10.1161/ 01.HYP.0000179581.68566.7d

40. Lorenzi-Filho G, Dajani HR, Leung RST, et al. Entrainment of blood pressure and heart rate oscillations by periodic breathing. $\mathrm{Am}$ J Respir Crit Care Med. 1999;159(4):1147-1154. doi:10.1164/ ajrccm.159.4.9806081
Nature and Science of Sleep

\section{Publish your work in this journal}

Nature and Science of Sleep is an international, peer-reviewed, open access journal covering all aspects of sleep science and sleep medicine, including the neurophysiology and functions of sleep, the genetics of sleep, sleep and society, biological rhythms, dreaming, sleep disorders and therapy, and strategies to optimize healthy sleep.
The manuscript management system is completely online and includes a very quick and fair peer-review system, which is all easy to use. Visit http://www.dovepress.com/testimonials.php to read real quotes from published authors. 